\title{
RAPID ASSIMILATION: AUTOMATICALLY INTEGRATING NEW INFORMATION WITH EXISTING BELIEFS
}

\author{
Colin Tucker Smith \\ Ghent University \\ Kate A. Ratliff \\ Tilburg University \\ Brian A. Nosek \\ University of Virginia
}

\begin{abstract}
The present research demonstrates rapid assimilation - the immediate integration of new information with existing beliefs. A vignette described generous and stringent welfare plans, one proposed by Democrats and one proposed by Republicans, manipulated between-subjects. Democrat and Republican participants were influenced by policy content, but also strongly influenced by the political party of the person proposing the plan. Participants underestimated the influence of party on their evaluations. Finally, the newly formed implicit evaluations mediated the effect of party information on self-reported evaluations, both immediately (Studies 1 and 2 ) and after a several-day delay (Study 2). The results suggest that (a) identity automatically influences evaluation separate from message content, (b) participants did not report awareness of this influence, and (c) when new information can assimilate to pre-existing social cognitions-such as one's political identity - then implicit evaluations form rapidly and show strength, durability, and predictive validity characteristic of well-elaborated evaluations.
\end{abstract}

Ask someone why they support or oppose the most recent legislation being debated in Congress and they are likely to provide reasons-judgments they believe are based on an analysis of the relevant information that led to their conclusion.

The authors thank the members of the University of Virginia Implicit Social Cognition Lab for their helpful comments. This research was supported by Project Implicit and Ghent University Grant BOF/ GOA2006/001.

Correspondence concerning this article should be sent to Colin Tucker Smith, Ghent University, Henri Dunantlaan 2, 9000 Ghent, Belgium. E-mail: colin.smith@ugent.be. 
They may explain that they formed their opinion after reading an article online, while watching a news segment detailing the legislation, or based on their own personal life experiences.

Counteracting the idea that people carefully and coldly arrive at their political positions, Campbell, Converse, Miller, and Stokes (1960) suggested that politicians' political party affiliations influence evaluations of candidates and the ideas they propose (see also Conover \& Feldman, 1989; Feldman \& Conover, 1983; Popkin, 1994; see also Lau \& Redlawsk, 2001 for a review of heuristics in political decision-making). Subjecting this idea to a psychological analysis, Cohen (2003) demonstrated that a bill being proposed by a Republican increases Republican and decreases Democratic support for it, regardless of the bill's content (and vice versa for Democrats). People's apparent lack of sensitivity to the influence of party over policy suggests that this process may occur automatically.

Bargh and Chartrand (1999) suggest that much of behavior is determined by automatic processes that operate outside of conscious awareness or control. Encountering a stimulus activates relevant associations with valence that then form the basis of automatic evaluative processes. The outcomes of those automatic evaluative processes may then be incorporated into the deliberate reasoning that generates explicit judgments (Gawronski \& Bodenhausen, 2006). The mere fact that a political party is associated with a proposed policy may activate party-relevant associations and fundamentally alter evaluation of the policy. For example, a selfidentified Democrat associates a new policy proposed by Democrats with her positive party evaluation. The identical policy details are then understood differently when associated with different parties, thereby reinforcing the influence of the party over the content itself. This leads her to automatically assimilate the policy proposed by her party as being an exemplar of her political identity, resulting in a positive automatic evaluation of the policy regardless of its details. Her automatic evaluation then forms the basis of her more deliberate judgment, leading to an explicit evaluation of the policy that is also favorable. This could occur even if the decision-maker intends to use policy content exclusively in guiding judgment, and even if the decision-maker subsequently believes that she was successful at avoiding partisan influence. In this way, past experience automatically guides the processing of similar new information (Smith \& DeCoster, 1998).

Evaluations of novel policies might be particularly easy to evaluate automatically because of existing, well-elaborated cognitions about their political identity. Theories of automatic evaluation have emphasized the extent to which associations may slowly accumulate and strengthen with experience (McClelland, McNaughton, \& O'Reilly, 1995; Rydell, McConnell, Strain, Claypool, \& Hugenberg, 2007; Wilson, Lindsey, \& Schooler, 2000). And, evidence suggests that elaboration increases the strength of the relationship between deliberate and automatic evaluations (Nosek, 2005). Studies that show single-learning attitude formation typically use stimuli with minimal connection with pre-existing knowledge structures to make clear that the evaluations are new, and not proxies for the pre-existing evaluations. For example, Gregg and colleagues (Gregg, Seibt, \& Banaji, 2006) formed automatic evaluations toward novel group members-Niffites and Luupites that intentionally bore little resemblance to existing groups (see also Ranganath \& Nosek, 2008; Ratliff \& Nosek, 2010). 
In the present research we offer a circumstance-perhaps a common one-in which automatic evaluations toward novel content may acquire the strength and durability of well-elaborated evaluations very quickly precisely because they are assimilated with the existing cognitions. If decision-makers can associate new information (e.g., a proposed policy) with pre-existing cognitions (e.g., political party identity), then the new information may be rapidly incorporated into the existing network and may also show characteristics similar to implicit evaluations that required substantial time and experience to form, strengthen, and influence judgment. In effect, rapid assimilation may be a means of minimizing or eliminating the need for extensive elaboration to create a strong automatic evaluation toward a novel concept.

We used Cohen's (2003) paradigm to test whether manipulating the party proposing a piece of legislation influences automatic evaluations of the legislation and whether those evaluations mediate the effects of the match between proposing party and participant party on explicit judgments both at the time of the manipulation (Studies 1 and 2) and after a multiple-day delay (Study 2). Based on the prior discussion, we expected the following to occur:

1. Both implicit and explicit evaluations of the policies will be influenced by the proposing party and by the policy content;

2. The relative impact of party compared to policy content will be stronger on implicit than explicit evaluations because the policy evaluation will be integrated with party affiliation automatically;

3. However, participants will not be able to completely avoid using information about the proposing party in explicit policy judgment, because it occurs automatically. That is, automatic evaluations will mediate the effect of the proposing party on explicit judgment of the policies;

4. The automatic evaluations of these novel policies will show the strength, durability and mediating influence characteristic of well-elaborated associations, despite being just a 2-minute exposure to the plans in a news article, thereby suggesting rapid assimilation of the new policies with pre-existing political evaluations.

\section{STUDY 1}

Participants read a vignette, presented in the form of a news article that outlined two competing welfare proposals, one referred to as the "Comprehensive Assistance Plan" and the other as the "Umbrella Aid Plan" (see Cohen, 2003). One plan was quite generous and the other more stringent. Between-subjects, we manipulated whether the generous plan was proposed by Democrats (and the stringent one by Republicans) or whether the generous plan was proposed by Republicans (and the stringent one by Democrats). After reading the news story, participants completed an Implicit Association Test (IAT; Greenwald, McGhee, \& Schwartz, 1998) measuring implicit evaluations of the two plans and also provided self-reported evaluations of the plans. 


\section{METHOD}

\section{Participants}

Participants were volunteers at the Project Implicit Virtual Laboratory (http: / /implicit.harvard.edu) and were randomly assigned to this study from a pool of dozens of studies. Participants were included if they were over 18 years old, completed all study materials, and were able to correctly identify the political party of the proposer of the generous welfare plan at the end of the study. The mean age of the 732 participants was 31.2 years $(S D=12.92) ; 64 \%$ were women. Fifty-two percent of participants reported being Democrats, 26\% reported being Republicans, and 22\% reported being neither Republican nor Democrat. Additionally, 79\% were White; $5 \%$ were Black, 3\% were Asian; and 13\% were Multiracial, Other, or Unknown. For more information about the Virtual Laboratory see Nosek (2005) and Nosek, Smyth, et al. (2007).

\section{Materials}

Welfare Plans. Participants read a brief vignette that was described as being similar to something that would appear in a newspaper (see Appendix). The fictitious news article described a policy debate in the legislature of an unnamed state over two proposed welfare plans. The generous plan (the Umbrella Aid Plan) was more generous than any existing welfare plan in the United States and the stringent plan (the Comprehensive Assistance Plan) was more stringent than any existing plan. Whether Republicans or Democrats proposed the generous plan was manipulated between-subjects.

Party Identification. Participants were asked, "With which political party do you most strongly identify?" Participants could choose "Republican," "Democrat," or "Neither." Participants who chose "Neither" will be referred to as "Independents."

Implicit Association Test. The IAT measures the strength of associations between concepts (e.g., Comprehensive Assistance Plan and Umbrella Aid Plan) and attributes (e.g., good and bad). Concept words included the names of the plans and prominent details (e.g., \$900/month, eight years; \$300/month, three years). Attribute words included positively and negatively valenced words (e.g., peace, sunshine; vomit, failure).

The IAT was conducted following the recommendations of Nosek and colleagues (Nosek, Greenwald, \& Banaji, 2005, 2007). In particular, participants began with 20 practice trials categorizing words related to "good" to the left using the " $\mathrm{e}$ " key and words related to "bad" to the right using the " $\mathrm{i}$ " key. They then categorized words related to the generous plan and the stringent plan for 20 trials using the same two keys. The first critical response block of 56 trials combined the first two tasks so that words related to both the generous plan and "good" were categorized with the " $\mathrm{e}$ " key, and words related to both the stringent plan and "bad" were categorized with the " $\mathrm{i}$ " key. Next, the attitude concepts (Umbrella Aid Plan, Comprehensive Assistance Plan) switched response keys, and participants practiced sorting this new arrangement for 40 trials. Having 40 instead of 20 trials in this reverse practice block minimizes a procedural artifact of task order (Nosek et al., 2005). Finally, the second critical block of 56 trials required categorizing words related 
to both the generous plan and "bad" with the "e" key and the stringent plan and "good" with the " $\mathrm{i}$ " key.

An IAT score was calculated using the D-algorithm (Greenwald, Nosek, \& Banaji, 2003). Trials less than 400 milliseconds were dropped and latencies for all trials were calculated from the onset of the stimulus until the correct response was made. We did not use IAT data from 19 out of the 732 participants (2.5\%) because of too high error rates (greater than $40 \%$ in a single block or greater than $30 \%$ overall), resulting in IAT scores for 713 participants. Positive scores indicate an implicit preference for the generous welfare plan over the stringent plan. Split-half reliability of this IAT was $r=.61$.

Explicit Judgments. Participants rated their relative preference by responding to "Which of the two welfare plans that you read about do you prefer?" using a 7-point scale, ranging from -3 to +3 and anchored by "I strongly prefer the Umbrella Aid Plan to the Comprehensive Assistance Plan" and "I strongly prefer the Comprehensive Assistance Plan to the Umbrella Aid Plan." Positive scores indicate an explicit preference for the generous welfare plan over the stringent plan.

\section{Procedure}

Participants registered an identity at the Project Implicit research website minutes to months prior to being assigned to this study. After logging in, participants were randomly assigned to this study from a pool of available studies. After being assigned once, participants could not be assigned to the study again on future visits. Participants first read the news article outlining the two competing welfare proposals (one generous and one stringent). Which proposal was backed by which party was manipulated between-subjects. After reading the news story, participants completed an IAT measuring automatic evaluations of the two plans and provided self-reported evaluations of the plans. The order of evaluation measures was randomized and did not qualify any of the reported results. Finally, participants reported their political party. ${ }^{1}$

\section{RESULTS}

On all measures, a positive score indicates a preference for the generous over the stringent welfare plan; implicit and explicit evaluations of the welfare plans were positively correlated, $r(711)=.48, p<.0001$.

1. As political identity serves as the moderator in the meditational analyses reported in this article, it is preferable to measure it before the independent variable in order to ensure that the two are uncorrelated. However, in this work we wanted to avoid making the participants' own political parties overly salient. As such, we measured political party after manipulating the independent variable. While we, therefore, cannot be certain that participants' self-reported political party was not affected by whether a Democrat or a Republican proposed the generous welfare plan, we have indirect evidence that speaks to this point. Upon registering at the Project Implicit research website, participants report their political identity on a continuous scale from "Strongly Liberal" to "Strongly Conservative." While the liberal-conservative dimension does not entirely overlap with party identification, the two constructs are highly correlated ( $r=.63$; Abramowitz \& Saunders, 1998). When using the liberal-conservative item (which was measured before the independent variable) as the moderator, each of the analyses in the current work is replicated. Please contact the first author for the details of these analyses. 

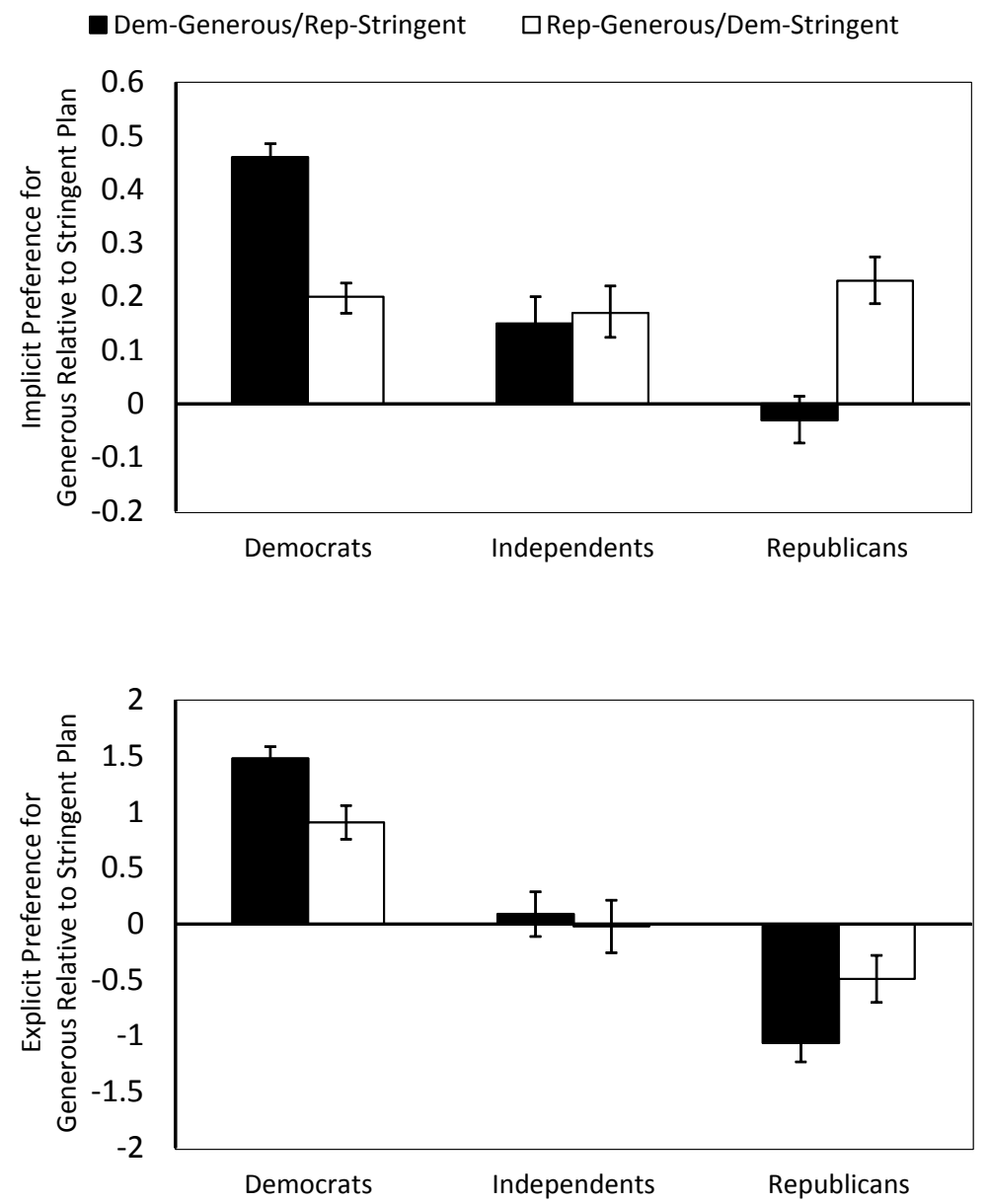

FIGURE 1. Study 1 results: the top panel of the figure shows the results for implicit evaluations and the bottom panel shows the results for explicit judgments toward the welfare plans as a function of political identity and political party of the plans' proposers. A positive score indicates a preference for the generous over the stringent welfare plan and a negative score indicates a preference for the stringent over the generous plan.

\section{Proposing Party Influenced Policy Evaluation both Implicitly and Explicitly}

Whether participants' political identification influenced evaluations of the welfare plans proposed by Republicans or Democrats was tested with two separate 3 (Participant Political Party: Republican, Democrat, or Independent) $\times 2$ (Proposer Political Party: Democrat Stringent/Republican Generous or Democrat Generous / Republican Stringent) ANOVAs for implicit and explicit evaluations. See Figure 1 for observed means.

Implicit Evaluations. As hypothesized, there was a significant interaction between participant political party and proposer political party on implicit evaluations, $F(2$, $707)=27.06, p<.0001, \eta^{2}=.071$. Democrats showed a stronger implicit preference for the generous welfare plan when it was proposed by a Democrat $(M=0.46$, $S D=0.37)$ than by a Republican $(M=0.20, S D=0.39), t(372)=6.72, p<.0001, d$ $=0.68$. Republicans, on the other hand, showed a stronger implicit preference for the generous welfare plan when it was proposed by a Republican $(M=0.23, S D$ 
TABLE 1. Study 1 Mediated-Moderation Results

\begin{tabular}{|c|c|c|c|c|c|c|}
\hline & \multicolumn{2}{|c|}{$\begin{array}{c}\text { Equation 1: Explicit } \\
\text { Evaluations }\end{array}$} & \multicolumn{2}{|c|}{$\begin{array}{c}\text { Equation 2: Implicit } \\
\text { Evaluations }\end{array}$} & \multicolumn{2}{|c|}{$\begin{array}{c}\text { Equation 3: Explicit } \\
\text { Evaluations }\end{array}$} \\
\hline & $b$ & $t$ & $b$ & $t$ & $b$ & $t$ \\
\hline IV: Proposer Political Party & -0.56 & $-2.15^{*}$ & -0.26 & $-4.52^{* * *}$ & -0.11 & -0.43 \\
\hline MO: Participant Political Party & 1.40 & $6.13^{* * *}$ & -0.03 & -0.61 & 1.45 & $6.79^{* * *}$ \\
\hline $\mathrm{IV} \times \mathrm{MO}$ & 1.13 & $3.54 * *$ & 0.52 & $7.43^{* * *}$ & 0.24 & 0.78 \\
\hline ME: IAT & & & & & 1.74 & $5.97 * * *$ \\
\hline $\mathrm{ME} \times \mathrm{MO}$ & & & & & -0.08 & -0.22 \\
\hline
\end{tabular}

Note. IV = Independent Variable, $\mathrm{MO}=$ Moderator Variable, ME $=$ Mediator Variable; ${ }^{*} p<.05,{ }^{* *} p<.01,{ }^{* * *} p<.0001$.

$=0.42)$ than by a Democrat $(M=-0.03, S D=0.42), t(183)=4.22, p<.0001, d=0.62$. Independents' implicit preferences did not differ based on whether the generous plan was proposed by a Democrat $(M=0.15, S D=0.49)$ or by a Republican $(M=$ $0.17, S D=0.35), t(152)=0.34, p=.74, d=0.05$.

Explicit Judgments. Replicating Cohen (2003), there was a significant interaction between participant political party and proposer political party on explicit judgment of the plans, $F(2,707)=6.10, p=.002, \eta^{2}=.017$. Democrats preferred the generous welfare plan more when it was proposed by a Democrat $(M=1.48, S D$ $=1.55)$ than by a Republican $(M=0.91, S D=1.92), t(372)=3.16, p=.002, d=0.33$. Republicans preferred the stringent plan more when it was proposed by a Republican $(M=-1.06, S D=1.64)$ than by a Democrat $(M=-0.49, S D=2.05), t(183)=2.05$, $p=.042, d=0.31$. Independents' preference for the generous plan was not affected by whether it was proposed by a Democrat $(M=0.09, S D=1.96)$ or a Republican $(M=-0.02, S D=1.79), t(152)=0.35, p=.73, d=0.06$.

Implicit Evaluations Mediated the Relationship between Political Affiliations and Explicit Judgments. A key interest is whether the newly formed implicit evaluations mediated the effect of participant party/proposer party on explicit judgments. To test this hypothesis, we followed the recommendations of Muller, Judd, and Yzerbyt (2005) for assessing mediated moderation. In order to estimate and present beta-weights for the analysis, only two levels of participant political party were included in the analysis - those who identified as Republicans and those who identified as Democrats. ${ }^{2}$ According to Muller et al. (2005), there are three conditions that must be met in order to show that mediated moderation has occurred. Condition 1: The interaction between the independent variable (proposer political party) and the moderator (participant political party) must be significant. Condition 2: Either (a) the interaction between the independent variable and moderator has a significant effect on the mediator (implicit attitude) AND the mediator (implicit attitude) has a significant effect on the outcome (explicit attitude), or (b) the effect of the independent variable (proposer political party) on the mediator (implicit attitude) is

2. Significance tests for the mediated-moderation results reported below were mirrored when including data from Independents. Specifically, explicit judgments were significantly predicted by the interaction between Participant Political Party and Proposer Political Party, $F(2,707)=6.10, p=.002$. However, when implicit evaluations (mean-centered) in addition to the interaction between implicit evaluations and participant political party were added to the regression equation in a second step, the interaction between participant political affiliation and proposer political affiliation on explicit judgment was reduced close to zero, $F(2,704)=0.37, p=.69$ indicating full mediation. 
significant AND the interaction effect between the moderator (participant political party) and mediator (implicit attitude) on the outcome variable is also significant. Condition 3: The effect of the interaction between the independent variable and the moderator on the outcome variable (proposer political party $\times$ participant political party) should lose significance or be reduced in magnitude when the mediator (implicit attitude) and the interaction between the mediator (implicit attitude) and the moderator (participant political party) is controlled for in the model.

Our model meets each of these conditions as reported below (see Table 1). The levels of the independent variables were coded as follows: Participant Political Party $($ Republican $=-1$; Democrat $=1$ ) and Proposer Political Party (Democrat Stringent/Republican Generous $=-1$; Democrat Generous/Republican Stringent $=1$ ).

As in the ANOVA results reported above, explicit judgments were significantly predicted by Participant Political Party, $b=1.40, t=6.13, p<.0001$, Proposer Political party, $b=-0.56, t=-2.15, p=.032$, and, most importantly for the mediated moderation analysis, by the interaction between Participant Political Party and Proposer Political Party, $b=1.13, t=3.54, p=.0004$. However, when implicit evaluations (mean-centered) in addition to the interaction between implicit evaluations and participant political party (i.e., the moderator) were added to the regression equation in a second step, the interaction between participant political affiliation and proposer political affiliation on explicit judgment was reduced close to zero, $b$ $=0.24, t=0.78, p=.44$, while implicit evaluations (i.e., the mediator) were a significant predictor, $b=1.74, t=5.97, p<.0001$. This suggests that the variance in participants' explicit judgment of the welfare plans was fully mediated by their implicit reactions toward the plans. Importantly, the reverse was not true; the variance in implicit evaluation was not accounted for by explicit judgments (mean-centered) as the interaction of participant and proposer remained significant even after explicit judgments (and the interaction between explicit judgments and participant political party) were entered into the regression equation, $b=0.43, t=6.47, p<$ .0001 .

\section{DISCUSSION}

Study 1 showed that implicit evaluations can form immediately and automatically on the basis of existing beliefs. Republicans showed a stronger implicit and explicit preference for a welfare plan proposed by a Republican than by a Democrat even when the two plans were identical. Democrats showed a stronger preference for the plan when it was proposed by a Democrat than by a Republican. Independents-whose own political identities are not captured by the proposer of either plan-were not systematically affected by the party membership of the plans' proposers. Cohen (2003) established this effect for self-reported political judgments among strongly partisan participants. The present study shows that: (1) the party over policy effect occurs implicitly and (2) implicit evaluations of the welfare plans mediate explicit judgments.

The newly formed implicit evaluations toward the welfare plans completely mediated the interaction between the political party of the plan proposer and the political party of the participant on explicit judgments, suggesting that the influ- 
ence of proposing party occurs automatically. As anticipated, the effect of party proposer on implicit evaluations was about twice the size of the effect on explicit judgment which may indicate that participants are engaging in some corrective processes explicitly (though they are not able to completely undo the automatic influence of political party on their policy preference). As such, the shift in implicit evaluations was sufficient to account for the explicit judgments. However, explicit judgments - which presumably were adjusted deliberately based on other beliefs, desires not to be influenced by party, etc.-were not sufficient to account for the influence of the experimental manipulation on implicit evaluations.

It is possible, however, that the observed assimilation is ephemeral and/or is not indicative of true assimilation of the new policies into existing knowledge structures. One of the hallmarks of strong evaluations is that they persist over time (Petty, Haugtvedt, \& Smith, 1995). As such, in Study 2, we sought to test the robustness and durability of the current effect by (a) investigating whether participants have subjective knowledge of their reliance on party information, (b) replicating the rapid assimilation effect on implicit and explicit evaluations, (c) replicating the evidence that implicit evaluations mediate the manipulation's effect on explicit judgments, and (d) extending both effects across a multiple day time lag.

\section{STUDY 2}

Study 2 was designed to replicate the findings of Study 1 and extend them across a multiple-day lag. If this effect is durable, it would lend confidence to our claim that the rapidly formed implicit evaluations have properties of strong evaluations. Also, measures of self-perceptions of the influence of both the details of the plans and the party of the plans' proposers were included to assess whether participants reported subjective awareness of how their evaluations were being formed.

\section{METHOD}

\section{Participants}

Participants were 621 volunteers at the Project Implicit Virtual Laboratory (see Study 1) who completed all presented measures at both an initial session and a follow-up session in addition to correctly identifying which party presented the generous welfare plan. Mean age was 34.4 years $(S D=13.27) ; 72 \%$ women; $66 \%$ of participants reported being Democrats, 16\% Republicans, and 18\% reported identifying with neither political party. Additionally, 86\% were White; 3\% were Black, $3 \%$ were Asian; and $8 \%$ were Multiracial, Other, or Unknown. ${ }^{3}$

3. Participants who returned for the second session were slightly older ( $M$ age $=34.4$ years, $S D$ $=13.27$ years $)$ than those who did not $(M$ age $=30.9$ years, $S D=12.23), t(3621)=7.13, p<.0001, d$ $=0.27$. On a scale ranging from 3 (Very Liberal) to -3 (Very Conservative), those participants who completed the second session were slightly more liberal $(M=1.09, S D=1.67)$ than those who did not $(M=0.79, S D=1.70), t(3029)=3.90, p<.0001, d=0.18$. Importantly, drop-out rate was constant across experimental condition and the larger sample at Time 1 shows the same pattern of results reported here for the subsample at Time 1. 


\section{Materials and Dependent Measures}

All materials and dependent measures are identical to that of Study 1 with the addition of questions at Time 1 measuring participants' self-theories regarding the information that influenced their judgments of the welfare plans. Split-half reliability of the IAT was $r=.65$ at Time 1 and $r=.68$ at Time 2 .

Self-Perceived Influences on Policy Evaluations. Participants reported how much the party information and plan information affected their evaluations of the plans by responding to two questions ("Please estimate the extent to which the specific details of the proposals contributed to your preference" and "How much did the political party affiliated with the welfare proposals influence your level of support?") where 1 = "none" and 5 = "a great deal."

\section{Procedure}

Participants followed the procedure and materials described in Study 1 (with the addition of the two questions about self-perceived influences on their evaluations which were presented following the measurement of implicit and explicit evaluations). At the end the first session, participants were asked whether the experimenters could contact them for a follow-up session. Those who consented were sent a link to a second study session approximately two days after the completion of the first study. The second session consisted of the completion of the same IAT and explicit item presented in the first session without any direct reminders of which party proposed which plan. The order of the measures of implicit and explicit evaluations was randomized across participants in both sessions and did not influence any study results. The average length of time between the initial session and the follow-up session was 5 days.

\section{RESULTS}

A positive score on all measures indicates a preference for the generous over the stringent welfare plan; implicit and explicit evaluations of the welfare plans were positively correlated at Time $1, r(619)=.51, p<.0001$ and Time $2, r(619)=.59, p<$ .0001 . The correlation between implicit and explicit evaluations was significantly stronger at follow-up than at the initial session $(z=2.02, p=.043)$, possibly suggesting that participants relied more on their implicit evaluations as the specific details were forgotten (see Ranganath \& Nosek, 2008).

\section{Time 1 Results}

Perceptions of Influences on Evaluations. Participants reported relying on the details of the plans $(M=3.85, S D=1.04)$ much more than they reported relying on the party of the plans' proposers $(M=2.11, S D=1.11), t(619)=27.95, p<.0001, d$ $=0.81 ; 39.5 \%$ said that the parties proposing the plans had no influence on their judgment, whereas only $3.9 \%$ said that the policy details had no impact. In contrast, $29.4 \%$ said that the policy details had "a great deal" of impact, whereas only $2.3 \%$ said that for party information. 
Dem-Generous/Rep-Stringent $\square$ Rep-Generous/Dem-Stringent
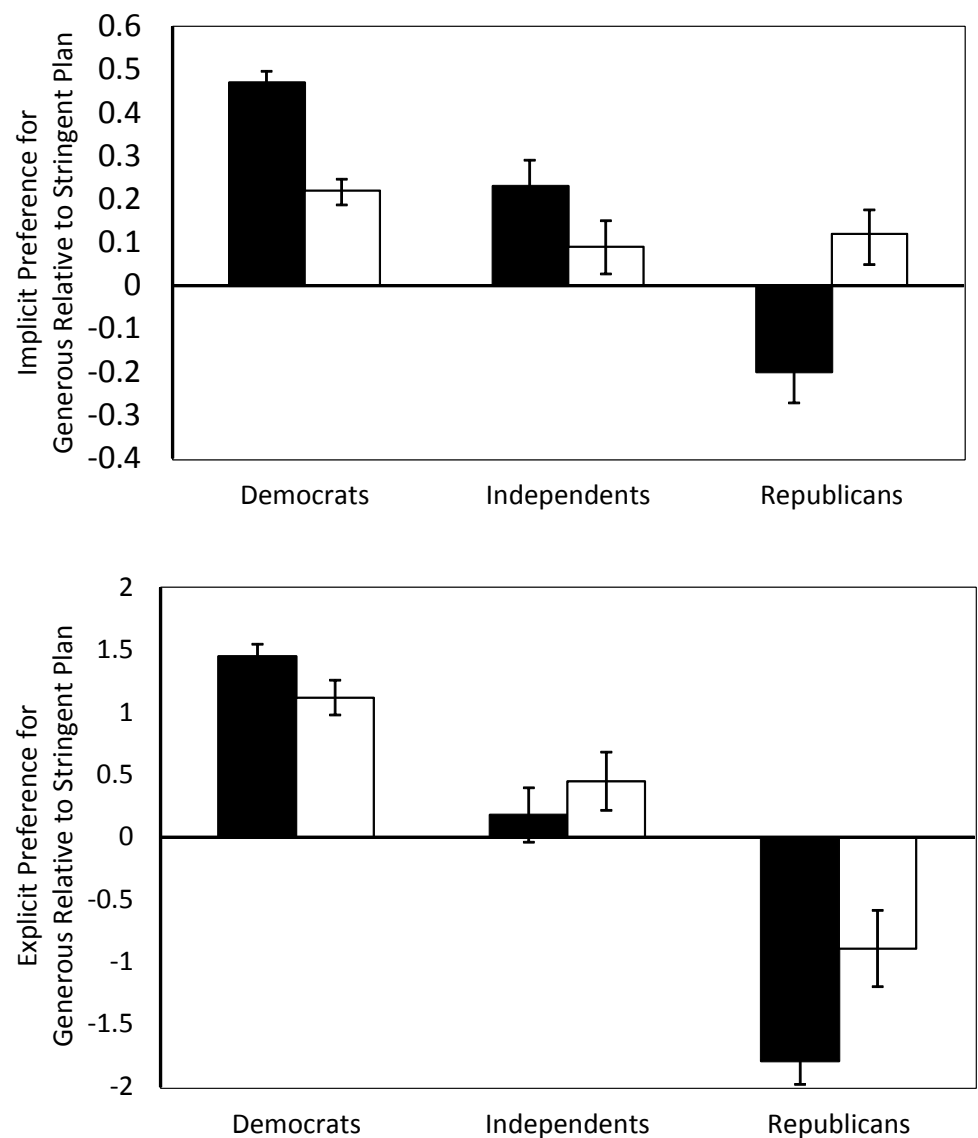

FIGURE 2. Study 2, Time 1 results: the top panel of the figure shows the results for implicit evaluations and the bottom panel shows the results for explicit judgments toward the welfare plans as a function of political identity and political party of the plans' proposers. A positive score indicates a preference for the generous over the stringent welfare plan and a negative score indicates a preference for the stringent over the generous plan.

Implicit Evaluations. A 3 (Participant Political Party: Republican, Democrat, or Independent) $\times 2$ (Proposer Political Party: Democrat Stringent/Republican Generous or Democrat Generous/Republican Stringent) ANOVA was used to test whether participants' political identification influenced evaluations of welfare plans proposed by Republicans or Democrats. See Figure 2 for observed means.

As in Study 1, there was a significant interaction between participant political party and proposer political party on implicit evaluations, $F(2,615)=17.25, p<$ $.0001, \eta^{2}=.053$. Democrats showed a stronger implicit preference for the generous welfare plan when it was proposed by a Democrat $(M=0.47, S D=0.38)$ than by a Republican $(M=0.22, S D=0.47), t(408)=6.02, p<.0001, d=0.58$. Republicans, on the other hand, showed a stronger implicit preference for the generous welfare plan when it was proposed by a Republican $(M=0.12, S D=0.49)$ than by a Democrat $(M=-0.20, S D=0.40), t(97)=3.55, p=.0006, d=0.72$. Independents showed no difference in their implicit preference for the generous welfare plan based on 
whether it was proposed by a Democrat $(M=0.23, S D=0.47)$ or a Republican $(M$ $=0.09, S D=0.45), t(110)=1.58, p=.12, d=0.30$.

We then tested whether the influence of participant political party and proposer political party on implicit evaluations could be explained by perceived influence of the proposing party. That is, does the extent to which participants report being influenced by the proposing party affect how influenced they actually are. We entered perceived influence as a covariate after centering it on its mean; the interaction of participant and proposer political party remained reliable even after accounting for the self-perceived influence of the proposing party, $F(2,614)=$ $17.53, p<.0001, \eta^{2}=.054$. In fact, the effect is nearly identical to the analysis that did not include the self-perception covariate. This suggests that the self-perceived influence was unrelated to actual influence of the proposing party.

Explicit Judgments. There was a significant interaction between participant political party and proposer political party on explicit judgment of the plans, $F(2,615)$ $=6.59, p=.002, \eta^{2}=.020$. Democrats preferred the generous welfare plan more strongly when proposed by a Democrat $(M=1.45, S D=1.42)$ than by a Republican $(M=1.12, S D=1.96), t(408)=2.02, p=.044, d=0.19$. Republicans preferred the stringent plan more when it was proposed by a Republican $(M=-1.79, S D=1.36)$ than by a Democrat $(M=-0.89, S D=2.10), t(97)=2.54, p=.013, d=0.51$. Independents showed a nonsignificant, stronger explicit preference for the generous welfare plan when it was proposed by a Democrat $(M=0.18, S D=1.70)$ rather than a Republican $(M=-0.45, S D=1.67), t(96)=1.86, p=.07, d=0.37$.

We tested whether the influence of participant political party and proposer political party on self-reported judgments could be explained by perceived influence by entering it as a covariate after centering it on its mean; the interaction of participant and proposer political party remained reliable even after accounting for the self-perceived influence of the proposing party, $F(2,614)=6.26, p=.002, \eta^{2}=.02$. As with implicit evaluations, the effect is nearly identical to the analysis that did not include the self-perception covariate suggesting that the self-perceived influence was unrelated to actual influence of the proposing party.

Implicit Evaluations Mediated the Relationship between Political Affiliation and Explicit Judgments. Following the analysis procedure reported in Study 1, new implicit evaluations again mediated the effect of the interaction between the party of the plan's proposer and the party of the participant on explicit judgments (See Table 2). ${ }^{4}$

As in the ANOVA results reported above, explicit judgments were significantly predicted by Participant Political Party, $b=2.01, t=7.24, p<.0001$, Proposer Political Party, $b=-0.89, t=-2.60, p=.010$, and, most importantly for the mediated moderation analysis, by the interaction between Participant Political Party and Proposer Political Party, $b=1.23, t=3.22, p=.001$. However, when implicit evalu-

\footnotetext{
4. As in Study 1, significance tests for the mediated-moderation results reported below were mirrored when including data from Independents. Specifically, at Time 1, explicit judgments were significantly predicted by the interaction between Participant Political Party and Proposer Political Party, $F(2,615)=6.31, p=.002$. This interaction was reduced to nonsignificance when implicit evaluations were added to the regression equation, $F(2,612)=1.24, p=.29$ indicating full mediation. We likewise observed full mediation of explicit judgments at Time 2 by implicit evaluations at Time 1 as the significant interaction between Participant Political Party and Proposer Political Party, F(2, 615) $=7.61, p=.0005$ was reduced close to zero when implicit evaluations from Time 1 were added to the regression equation, $F(2,612)=0.88, p=.41$.
} 
TABLE 2. Study 2, Times 1 and 2, Mediated-Moderation Results

\begin{tabular}{|c|c|c|c|c|c|c|}
\hline \multirow[t]{2}{*}{ Time 1} & \multicolumn{2}{|c|}{$\begin{array}{c}\text { Equation 1: Explicit } \\
\text { Evaluations }\end{array}$} & \multicolumn{2}{|c|}{$\begin{array}{c}\text { Equation 2: Implicit } \\
\text { Evaluations }\end{array}$} & \multicolumn{2}{|c|}{$\begin{array}{c}\text { Equation 3: Explicit } \\
\text { Evaluations }\end{array}$} \\
\hline & $b$ & $t$ & $b$ & $t$ & $b$ & $t$ \\
\hline IV: Proposer Political Party & -0.89 & $-2.60 * *$ & -0.32 & $-3.71 * *$ & -0.29 & -0.85 \\
\hline MO: Participant Political Party & 2.01 & $7.24 * * *$ & 0.1 & 1.5 & 1.79 & $6.86^{* * *}$ \\
\hline$I V \times M O$ & 1.23 & $3.22^{* *}$ & 0.57 & $5.95^{* * *}$ & 0.24 & 0.66 \\
\hline ME: IAT & & & & & 1.9 & $5.34^{* * *}$ \\
\hline $\mathrm{ME} \times \mathrm{MO}$ & & & & & -0.4 & -0.99 \\
\hline \multirow[t]{2}{*}{ Time 2} & \multicolumn{2}{|c|}{$\begin{array}{c}\text { Equation 1: Explicit } \\
\text { Evaluations }\end{array}$} & \multicolumn{2}{|c|}{$\begin{array}{c}\text { Equation 2: Implicit } \\
\text { Evaluations }\end{array}$} & \multicolumn{2}{|c|}{$\begin{array}{c}\text { Equation 3: Explicit } \\
\text { Evaluations }\end{array}$} \\
\hline & $b$ & $t$ & $b$ & $t$ & $b$ & $t$ \\
\hline IV: Proposer Political Party & -0.97 & $-2.93 * *$ & -0.32 & $-3.71^{* *}$ & -0.38 & -1.17 \\
\hline MO: Participant Political Party & 1.93 & $7.22 * * *$ & 0.1 & 1.5 & 1.72 & $6.88^{* * *}$ \\
\hline$I V \times M O$ & 1.45 & $3.91^{* *}$ & 0.57 & $5.95^{* * *}$ & 0.47 & 1.31 \\
\hline ME: IAT & & & & & 1.86 & $5.45^{* * *}$ \\
\hline $\mathrm{ME} \times \mathrm{MO}$ & & & & & -0.34 & -0.89 \\
\hline
\end{tabular}

Note. IV = Independent Variable, $\mathrm{MO}=$ Moderator Variable, ME $=$ Mediator Variable; ${ }^{*} p<.05,{ }^{* *} p<.01,{ }^{* * *} p<.0001$.

ations (mean-centered) in addition to the interaction between implicit evaluations and participant political party (i.e., the moderator) were added to the regression equation in a second step, the interaction between participant political affiliation and proposer political affiliation on explicit judgment was reduced close to zero, $b$ $=0.24, t=0.66, p=.51$, while implicit evaluations (i.e., the mediator) were a significant predictor, $b=1.90, t=5.34, p<.0001$. This suggests that the variance in participants' explicit judgment of the welfare plans was fully mediated by their implicit reactions toward the plans. Importantly, the reverse was not true; the variance in implicit evaluation was not accounted for by explicit judgments (mean-centered) as the interaction of participant and proposer remained significant even after explicit judgments (and the interaction between explicit judgments and participant political party) were entered into the regression equation, $b=0.43, t=4.73, p<.0001$.

\section{Time 2 Results}

Implicit Evaluations. There was a significant interaction between participant political party and proposer political party on implicit evaluations measured at Time 2 , an average of 5.1 days after the initial session, $F(2,615)=12.60, p<.0001, \eta^{2}=$ $.039 .{ }^{5}$ See Figure 3 for observed means. Democrats showed a stronger implicit pre-

5. Our experimental design cannot rule out the possibility that measurement at Time 1 influenced the observed evaluations at Time 2 but it is unlikely for several reasons. First, participants perform both critical conditions in the IAT at Time 1, with the exact same number of blocks and trials. So, they learn how to perform the IAT, but there is no privileging of one association over another. Second, Greenwald et al. (2003) demonstrated that experience with the IAT usually leads to a decline in the sensitivity of the IAT to detect associations; however, the fact that association strengths at Time 2 are as strong as they were at Time 1 is counter to that effect. Third, there were multiple days between Time 1 and 2 measurements, decreasing the likelihood that any specific response strategies employed at Time 1 would have carried over to Time 2 (not to mention it being unclear what response strategies would have produced spurious durability effects). And, finally, there is empirical evidence that stimulus familiarity is not a substantial source of IAT artifacts (see Dasgupta, Greenwald, \& Banaji, 2003, for a review). 

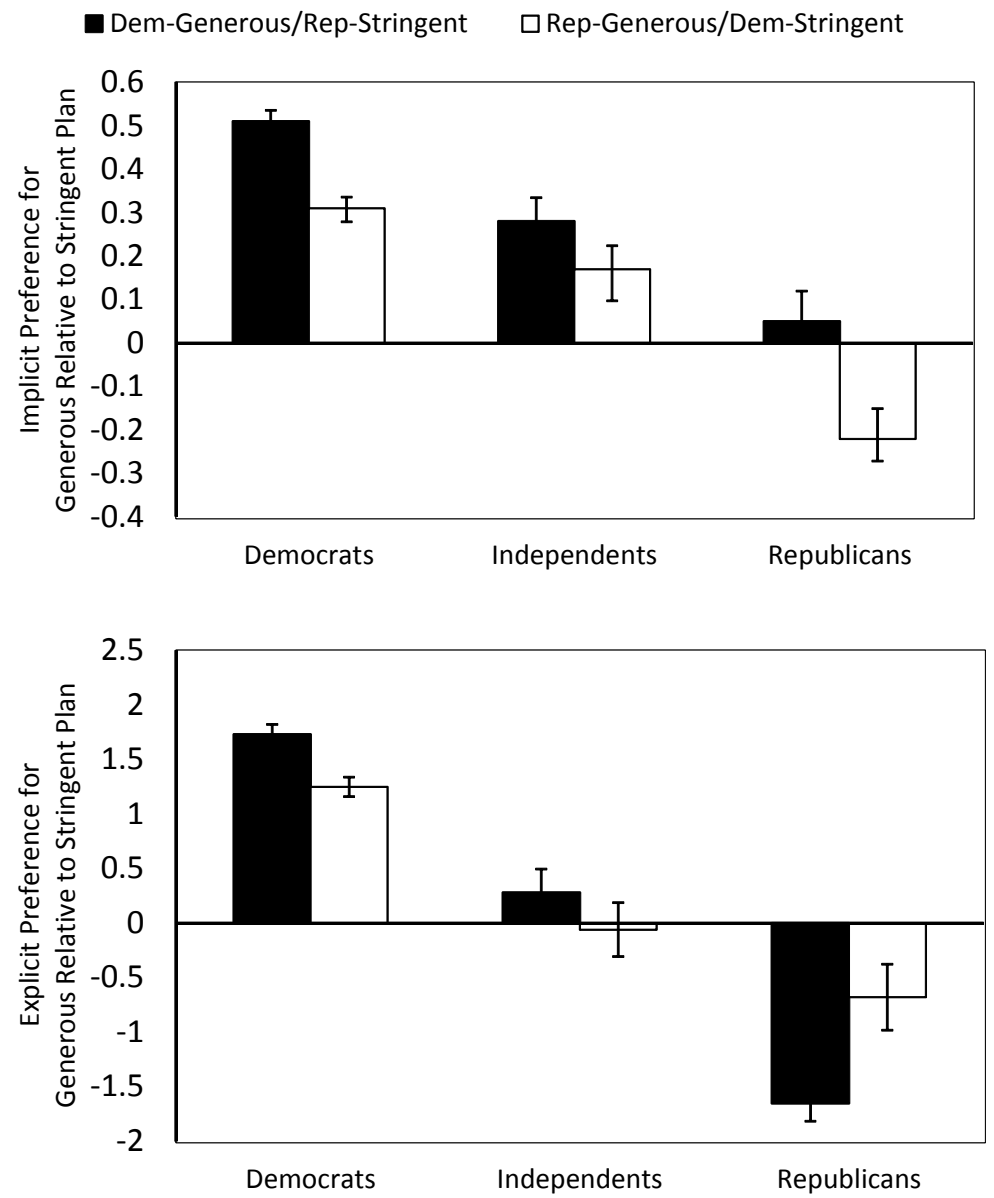

FIGURE 3. Study 2, Time 2 results: the top panel of the figure shows the results for implicit evaluations and the bottom panel shows the delayed results for explicit judgments toward the welfare plans as a function of political identity and political party of the plans' proposers. A positive score indicates a preference for the generous over the stringent welfare plan and a negative score indicates a preference for the stringent over the generous plan.

ference for the generous welfare plan when it was proposed by a Democrat $(M=$ $0.51, S D=0.36)$ than by a Republican $(M=0.31, S D=0.45), t(408)=5.07, p<.0001$, $d=0.49$. Republicans, in contrast, showed a stronger implicit preference for the generous welfare plan when it was proposed by a Republican $(M=0.05, S D=0.50)$ than by a Democrat $(M=-0.22, S D=0.35), t(97)=3.15, p=.002, d=0.63$. Again, Independents did not prefer the generous plan more when it was proposed by a Democrat $(M=0.28, S D=0.42)$ than by a Republican $(M=0.17, S D=0.52), t(110)$ $=1.25, p=.21, d=0.23$.

We also tested whether the amount of time between the first and second sessions moderated the observed interactive effect. Participants returned for Session 2 after an average of 5.1 days, with substantial variation around the mean $(S D=$ 6.13; Minimum = 14 hours; Maximum = 39 days). If the durability effect dissipated rapidly over time, then we would likely be more cautious about this study being 
evidence of rapid assimilation. We tested this with a regression analysis by regressing implicit evaluations onto participant political party, political party of the plans' proposers, and the number of days between the two sessions. The 3-way interaction, each of the 2-way interactions, and the three main effects were all entered simultaneously in the model. The interaction of participant political party and proposer political party on implicit evaluations remained reliable and strong after accounting for the time between sessions, $F(2,609)=12.01, p<.0001$. However, there was a 3-way interaction with length of time between sessions significantly moderating the interaction effect between participant and proposing party, $F(2$, $609)=3.64, p=.027$, indicating that the size of the interaction effect of participant and proposing party on implicit evaluations may fluctuate across time. When we dropped the data from the 16 participants (2.6\% of sample) whose time between sessions was more than three standard deviations away from the mean ( 25 days or more between sessions), the 3-way interaction was no longer significant, $F(2,593)$ $=0.67, p=.51$, while-as before-the interaction of participant political party and proposer political party on implicit evaluations was reliable and strong, $F(2,593)$ $=12.72, p<.0001$. This suggests that the impact of participant political party and proposer political party on implicit evaluations is monotonic at least up to three weeks after the original manipulation.

Explicit Judgments. There was also a significant interaction between participant political party and proposer political party on explicit judgments of the plans at Time $2, F(2,615)=7.61, p=.0005, \eta^{2}=.024$. Democrats preferred the generous welfare plan more strongly when proposed by a Democrat $(M=1.73, S D=1.32)$ than by a Republican $(M=1.25, S D=1.94), t(408)=2.91, p=.004, d=0.29$. Republicans preferred the stringent plan more when it was proposed by a Republican $(M=$ $-1.65, S D=1.19)$ than by a Democrat $(M=-0.68, S D=2.07), t(97)=2.91, p=.005, d=$ 0.57. Independents' preference for the generous plan was not affected by whether it was proposed by a Democrat $(M=0.28, S D=1.69)$ or a Republican $(M=-0.06$, $S D=1.76), t(110)=1.03, p=.30, d=0.20$.

For self-reported judgments, after accounting for the time between sessions, the interaction of participant political party and proposer political party on evaluations remained reliable and strong, $F(2,609)=7.35, p=.0007$, and there was not a significant 3-way interaction between time between sessions, participant party and proposing party, $F(2,609)=0.58, p=.56$.

Implicit Evaluations at Time 1 Mediated the Relationship between Political Affiliations and Explicit Judgments at Time 2. In this mediated moderation analysis, implicit evaluations at the initial session were investigated as a mediator of the interaction between political party of the plans' proposer and political party of the participant on explicit judgments measured at the follow-up session. If the implicit evaluations formed at Time 1 mediate explicit judgments not only at Time 1, but also after a delay of several days, this would provide evidence that those evaluations are strong and durable.

As in the ANOVA results reported above, explicit judgments at Time 2 were significantly predicted by Participant Political Party, $b=1.93, t=7.22, p<.0001$, Proposer Political Party, $b=-0.97, t=-2.93, p=.004$, and by the interaction between Participant Political Party and Proposer Political Party, $b=1.45, t=3.91, p=.0001$. However, when implicit evaluations (mean-centered) along with the interaction between implicit evaluations and participant political party (i.e., the moderator) 
were added to the regression equation in a second step, the interaction between Participant Political Party and Proposer Political Party on explicit judgment was reduced to nonsignificance, $b=0.47, t=1.31, p=.19$, while implicit evaluations were a significant predictor, $b=1.86, t=5.45, p<.0001$. This suggests that the variance in participants' explicit judgment of the welfare plans was fully mediated by their implicit reactions toward the plans. Importantly, the reverse pattern was not observed; the variance in implicit evaluation was not accounted for by explicit judgments (mean-centered) as the interaction of Participant Political Party and Proposer Political Party remained significant even after explicit judgments (and the interaction between explicit judgments and Participant Political Party) were entered into the regression equation, $b=.35, t=4.05, p<.0001 .^{6}$

\section{DISCUSSION}

The results from Study 2 provide additional evidence that new implicit evaluations can form rapidly through assimilation with existing beliefs-in this case, political party identity. Democrats again showed a stronger implicit and explicit preference for a welfare plan proposed by a Democrat than by a Republican, even when the two plans were exactly the same. Similarly, Republicans showed a stronger preference for the plan when it was proposed by a Republican than by a Democrat. Independents were again unaffected by information about the proposers' political parties. Participants were inaccurate about the extent to which party information influenced their judgment; the extent to which they reported that it mattered did not account for the party over policy effects implicitly or explicitly. Importantly, implicit evaluations of the plans remained strong five days after the exposure to them. Perhaps of most interest, implicit evaluations at the initial session mediated the influence of the manipulation on explicit judgments at the second session. This is the first time that implicit evaluations have been shown to mediate self-reported evaluations that are measured after a multiple-day lag. Finally, the correlation between implicit and explicit judgments was actually stronger at Time 2 compared to Time 1 suggesting that some of the explicit, corrective processes that may have altered explicit judgment at Time 1 were lost as memory for the details of the plans faded (see also Ranganath \& Nosek, 2008). As a consequence, the basis for explicit judgment at Time 2 was more dependent on the implicit reaction to the plans. These findings suggest that, rather than being fleeting constructions, these newly formed implicit evaluations exhibit the properties of strong, well-elaborated evaluations (Krosnick \& Petty, 1995; Pomerantz, Chaiken, \& Tordesillas, 1995).

\section{GENERAL DISCUSSION}

Results from the present studies suggest that the formation of implicit evaluations can occur rapidly and show the durability (Study 2) and predictive validity (Study

\footnotetext{
6. Implicit evaluations measured at Time 2 also mediated the interactive effect of political party of the plans' proposer and the participant on explicit judgments at Time 2, as the interaction was reduced to nonsignificance, $b=0.56, t=1.68, p=.095$ while implicit evaluations were a significant predictor, $b=1.69, t=4.99, p<.0001$.
} 
1 and Study 2) that is normally expected of strong, well-elaborated evaluations. In these studies, the party proposing a new policy provided a cue for linking evaluations of the novel policy to pre-existing knowledge structures-the person's political party affiliation. This effectively bypasses the need to elaborate extensively on the new information to achieve strong evaluations. That rapid assimilation occurred is supported by multiple pieces of evidence:

1. Replicating and extending prior research which relied solely on self-report, Republicans showed a stronger explicit and implicit preference for a welfare plan proposed by a Republican than for an identical plan proposed by a Democrat, while Democrats showed a stronger explicit and implicit preference for a welfare plan proposed by a Democrat than for an identical plan proposed by a Republican. Independents-for whom party information was not personally relevant-appeared mostly unaffected by the party of the plans' proposers.

2. The liking of the plan based on the interaction between the party of the proposer and the party of the participant was more impactful on the implicit measure than on the explicit measure suggesting that, implicitly, participants assimilated their policy preference to their political affiliation, and, explicitly, engaged corrective processes that partly resisted this influence. However, that corrective processing was not sufficient to prevent the influence of the proposing party on explicit judgments.

3. The newly formed implicit evaluations were strong, persisted over time, and correlated strongly with the explicit judgments immediately following their formation (Study 1, $r=.48$; Study 2, $r=.51$ ), and even more strongly after a multiple-day delay (Study 2, $r=.59$ ). This suggests durability of the brief exposure to the policy plans, and consolidation of their implicit and explicit judgments, presumably because the details of the learning episode - and basis for corrective processing-were being forgotten leaving only the associative gist (Ranganath \& Nosek, 2008).

4. Implicit evaluations fully mediated the effect of the manipulation on explicit judgments, but the reverse was not true suggesting that the effect was automatic.

5. Participants did not report awareness of the effect of the proposing party on their evaluations. Whether they were actually unaware, or aware but unable to prevent the influence and declined to admit it is not known.

6. The mediation effect of implicit evaluations was durable in that it explained judgments occurring several days after the manipulation.

We suggest that rapid assimilation occurs when people use simple cues-such as group identity-to evaluate new information based on their existing beliefs instead of on the details of the new information. In this way, strong, automatic evaluations can form without elaborating on the new concepts themselves. In these studies, participants spent just a couple of minutes with the policy proposals, but show substantial evidence of strong and durable evaluations. There are at least two ways in which rapid assimilation might occur. One is that an individual's understanding of a policy plan's details is shaped by their evaluation of the proposing party. The other is that details are ignored altogether and the proposing party directly informs evaluations of the policy. Such practices dramatically simplify information processing by essentially considering the new information to be a proxy for the pre-existing beliefs-in this case beliefs about the valence of the 
political groups to which participants belong. For a group member, it is easier to decide one's opinion regarding a new policy by referencing its link to one's ingroup rather than investigating the details of the plan itself.

An interesting question for future research is whether the type of rapid assimilation effects that we have identified here are limited to identities and evaluations that are already extremely well-elaborated-such as politics-or whether assimilative processes also utilize other pre-existing knowledge structures that are more weakly elaborated. It seems plausible that any pre-existing cognitive structure could provide the basis of the rapid formation of evaluations of related novel content.

One factor that makes the current work so interesting is that we utilized a domain in which people are likely to have strong opinions; support for or opposition to welfare is strongly associated with the two dominant political parties in the United States. The fact that we observed that individuals implicitly and explicit preferred a plan that they "should" like (e.g., because Democrats should like generous welfare plans) significantly less when it was presented by a member of the opposite political party suggests that rapid assimilation can be a powerful phenomenon in attitude formation and change. Simple cues of identity and group membership can dramatically change evaluation of new content, even when the details of the content itself would lead the person to a different evaluation (Cohen, 2003).

Moreover, participants reported that they greatly attended to the details of the proposed welfare plans and only slightly attended to the political party of the plan's proposer; nonetheless, they showed a strong influence of proposing party whereby they implicitly and explicitly preferred a plan to a greater extent when it was proposed by a member of their own political party. The influence of proposing party was especially pronounced implicitly, suggesting that the effects are largely automatic. Importantly, implicit attitudes influenced judgments even when those explicit judgments were made several days later. Over time, as the details of the plans fade from memory, the explicit judgment may become even more in line with the initial implicit evaluation (Study 2 and Ranganath \& Nosek, 2008). So, even if a person is relatively effective in the short-term at focusing on the details of proposed legislation and overriding partisan influence, the simple fact that the plans have been assimilated to the party implicitly could produce a gradual drift back to partisan positioning. In this way, the rapid assimilation to one's group membership and identities may, over time, overwhelm the influence of the various details of policy positions and proposals. Knowing one's evaluation of a policy immediately may require attention both to their group membership and the details of the plan. But, knowing their evaluation of the policy eventually (as they cease to attend to the details) may require only knowing their group membership. Such cognitive factors may contribute to the polarizing of political discourse. 


\section{REFERENCES}

Abramowitz, A. I., \& Saunders, K. L. (1998). Ideological realignment in the U.S. electorate. Journal of Politics, 60, 634-652.

Bargh, J. A., \& Chartrand, T. L. (1999). The unbearable automaticity of being. American Psychologist, 54, 462-479.

Campbell, A., Converse, P., Miller, W. E., \& Stokes, D. (1960). The American voter. New York: Wiley.

Cohen, G. L. (2003). Party over policy: The dominating impact of group influence on political beliefs. Journal of Personality and Social Psychology, 85, 808-822.

Conover, P. J., \& Feldman, S. (1989). Candidate perception in an ambiguous world: Campaigns, cues, and inference processes. American Journal of Political Science, 33, 912-940.

Dasgupta, N., Greenwald, A. G., \& Banaji, M. R. (2003). The first ontological challenge to the IAT: Attitude or mere familiarity? Psychological Inquiry, 14, 238-243.

Feldman, S., \& Conover, P. J. (1983). Candidates, issues, and voters: The role of inference in political perception. Journal of Politics, 45, 810-839.

Gawronski, B., \& Bodenhausen, G. V. (2006). Associative and propositional processes in evaluation: An integrative review of implicit and explicit attitude change. Psychological Bulletin, 132, 692-731.

Greenwald, A. G., McGhee, D. E., \& Schwartz, J. L. K. (1998). Measuring individual differences in implicit cognition: The Implicit Association Test (IAT). Journal of Personality and Social Psychology, 74, 1464-1480.

Greenwald, A. G., Nosek, B. A, \& Banaji, M. R. (2003). Understanding and using the Implicit Association Test (IAT): I. An improved scoring algorithm. Journal of Personality and Social Psychology, 85, 197-216.

Gregg, A. P., Seibt, B., \& Banaji, M. R. (2006). Easier done than undone: Asymmetry in the malleability of implicit preferences. Journal of Personality and Social Psychology, 90, 1-20.

Krosnick, J. A., \& Petty, R. E. (1995). Attitude strength: An overview. In R. E. Petty \& J. A. Krosnick (Eds.), Attitude strength: Antecedents and consequences (pp. 1-24). Mahwah, NJ: Erlbaum.
Lau, R. R., \& Redlawsk, D. P. (2001). Advantages and disadvantages of cognitive heuristics in political decision-making. American Journal of Political Science, 45, 951-971.

McClelland, J. L., McNaughton, B. L., \& O'Reilly, R. C. (1995). Why are there complementary learning systems in the hippocampus and neocortex: Insights from the successes and failures of connectionist models of learning and memory. Psychological Review, 102, 419-457.

Muller, D., Judd, C. M., \& Yzerbyt, V. Y. (2005). When moderation is mediated and mediation is moderated. Journal of Personality and Social Psychology, 89, 852-863.

Nosek, B. A. (2005). Moderators of the relationship between implicit and explicit evaluation. Journal of Experimental Psychology: General, 134, 565-584.

Nosek, B. A., Greenwald, A. G., \& Banaji, M. R. (2005). Understanding and using the Implicit Association Test (IAT): II. Method variables and construct validity. Personality and Social Psychology Bulletin, 31, 166-180.

Nosek, B. A., Greenwald, A. G., \& Banaji, M. R. (2007). The Implicit Association Test (IAT) at age 7: A methodological and conceptual review. In J. A. Bargh (Ed.), Social psychology and the unconscious: The automaticity of higher mental processes (pp. 265-292). New York: Psychology Press.

Nosek, B. A., Smyth, F. L., Hansen, J. J., Devos, T., Lindner, N. M., Ranganath, K. A., Smith, C. T., Olson, K. R., Chugh, D., Greenwald, A. G., \& Banaji, M. R. (2007). Pervasiveness and correlates of implicit attitudes and stereotypes. European Review of Social Psychology, 18, 36-88.

Petty, R. E., Haugtvedt, C., \& Smith, S. M. (1995). Elaboration as a determinant of attitude strength: Creating attitudes that are persistent, resistant, and predictive of behavior. In R. E. Petty \& J. A. Krosnick (Eds.), Attitude strength: Antecedents and consequences (pp. 93-130). Mahwah, NJ: Erlbaum.

Pomerantz, E. M., Chaiken, S., \& Tordesillas, R. S. (1995). Attitude strength and resistance processes. Journal of Personality and Social Psychology, 69, 408-419. 
Popkin, S. L. (1994). The reasoning voter, second edition. Chicago: University of Chicago Press.

Ranganath, K. A., \& Nosek, B. A. (2008). Implicit attitude generalization occurs immediately, explicit attitude generalization takes time. Psychological Science, 19, 249-254.

Ratliff, K. A., \& Nosek, B. A. (2010). Creating distinct implicit and explicit attitudes with an illusory correlation paradigm. Journal of Experimental Social Psychology, $46,721-728$.

Rydell, R. J., McConnell, A. R., Strain, L. M., Claypool, H. M., \& Hugenberg, K. (2007). Implicit and explicit attitudes re- spond differently to increasing amount of counterattitudinal information. European Journal of Social Psychology, 37, 867-878.

Smith, E. R., \& DeCoster, J. (1998). Knowledge acquisition, accessibility, and use in person perception and stereotyping: Simulation with a recurrent connectionist network. Journal of Personality and Social Psychology, 74, 21-35.

Wilson, T. D., Lindsey, S., \& Schooler, T. Y. (2000). A model of dual attitudes. Psychological Review, 107, 101-126.

\section{APPENDIX}

\section{STATE UNDECIDED ON NEW WELFARE LAW}

Republicans and Democrats remain deadlocked in the debate over the future of the state welfare program.

At the heart of the conflicts are benefits from Aid to Families with Dependent Children (AFDC) - the cash assistance provided to poor parents living below the poverty line. Along with food stamps and Medicaid, AFDC comprises the central tier of the welfare program, and it is where Republicans and Democrats disagree most vehemently. Each party has proposed a separate AFDC amendment to the current welfare statute.

Paul Koretz (D) [R] has proposed a plan that is supported by the majority of house Democrats [Republicans]. His plan, called the Comprehensive Assistance Plan, sets the benefits provided to poor families with a child at $\$ 250 /$ month - with an extra $\$ 50$ in payment for every additional child. Under this plan, a poor family with two children would be granted $\$ 300 /$ month in state funds-along with partial coverage for medical insurance through Medicaid. The proposal also imposes a lifetime limit of 1.5 years of benefits for those who are able-bodied.

The Democrats [Republicans] believe their plan, the Comprehensive Assistance Plan, to be fair and equitable. Democrat [Republican] Nathanial Llewellyn remarked, "This legislation is reasonable. It helps parents in need without undermining a basic work ethic and sense of personal responsibility."

On the other hand, Republicans [Democrats] assert that the program does not go far enough, and may ultimately hurt recipients by cutting off welfare to families still in need. They have proposed a counter-amendment, sponsored by Ray Hans (R) [D], called the Umbrella Aid Plan. Under that plan, the benefits to poor families with a child are set at $\$ 776 /$ month with an extra $\$ 200$ in payment for each additional child. Under this plan, a poor family with two children would be granted $\$ 976 /$ month-along with full Medicaid coverage. The proposal imposes an 8 year time limit on benefits for ablebodied parents. 
The Republicans [Democrats] argue that their proposed amendment, the Umbrella Aid Plan, is superior to that proposed by the Democrats [Republicans]. Republican [Democrat] William Glaser remarked, “The Democrats' [Republicans'] plan will only add to the burden of poor parents. The plan we have proposed is rational and just, and will serve to lighten the load for the state's poor by providing coverage where needed." 